\title{
Multidrug resistance affects the prognosis of primary epithelial ovarian cancer
}

\author{
BO GAO ${ }^{1,2}$, FENGMEI YANG ${ }^{3}$, WEI CHEN $^{2}$, RUI LI $^{4}$, XIUXUE HU $^{2}$, YONG LIANG $^{5}$ and DONGMIN LI \\ ${ }^{1}$ Department of Biochemistry and Molecular Biology, School of Basic Medical Sciences, \\ Xi'an Jiaotong University Health Science Center, Xi'an, Shanxi 710061; Departments of ${ }^{2}$ Laboratory Medicine, \\ ${ }^{3}$ Obstetrics and Gynecology and ${ }^{4}$ Medical Office, Taihe Hospital, Hubei University of Medicine; \\ ${ }^{5}$ Department of Anesthesiology, Ren-ming Hospital of Yun-xi, Shiyan, Hubei 442000, P.R. China
}

Received May 29, 2018; Accepted April 15, 2019

DOI: $10.3892 / \mathrm{ol} .2019 .10745$

\begin{abstract}
Multidrug-resistant tumor cells can tolerate different structures, functions and antidrug action mechanisms, therefore, allowing these cells to respond to various structurally unrelated mechanisms of different chemotherapy drugs and to exhibit cross-resistance. The present study aimed to investigate the role of Multi-drug resistance gene (MDR1), Placental glutathione S-transferase-P1 (GSTP1), Lung resistance protein (LRP) and Ras association domain family member 1 (RASSF1A) in primary epithelial ovarian cancer (PEOC). The mRNA (protein) expression levels of MDR1, product P glycoprotein, LRP and GSTP1 were evaluated with reverse transcription-quantitative polymerase chain reaction (RT-qPCR) and western blot analysis in all tissue samples, ovarian cancer cell line A2780 and A2780/DDP. Methylation-specific PCR (MSP) was used to detect RASSF1A gene methylation in all tissue samples. The resistance genes/proteins were either poorly or not expressed in A2780, however were highly expressed in A2780/DDP cell line. The expression of resistance genes/proteins decreased following different concentrations of zebularine-stimulated A2780/DDP. Hypermethylation and low expression of RASSF1A gene were detected in PEOC and A2780/DDP. Subsequent to being exposed to different concentrations of zebularine-stimulated A2780/DDP, the RASSF1A methylation level was decreased, while the unmethylation level was increased. The expression of RASSF1A gene/protein was gradually restored, and the gene/protein expression was enhanced with the increase in drug concentration. Multivariate logistic regression indicated that the expression level of gene LRP and GSTP1 was a risk
\end{abstract}

Correspondence to: Professor Dongmin Li, Department of Biochemistry and Molecular Biology, School of Basic Medical Sciences, Xi'an Jiaotong University Health Science Center, 76 Yanta West Road, Xi'an, Shanxi 710061, P.R. China

E-mail: lidongm@mail.xjtu.edu.cn

Key words: epithelial ovarian cancer, drug-resistant, Ras association domain family member 1 , methylation, zebularine factor for PEOC prognosis. Furthermore, the expression of LRP and GSTP1 in the negative-group survival curves was higher compared with the positive group. High expression of resistance genes may serve an important role in cancer primary resistance. Low expression caused by hyper-methylation of RASSF1A gene may serve an important role in cancer-acquired resistance in PEOC. The present study suggested that resistant gene expression may be a potential prognostic biomarker.

\section{Introduction}

Epithelial ovarian cancer (EOC) is a common malignant tumor found in the female reproductive system (1). Given its deep anatomical location, easy recurrence, easy metastasis and high susceptibility to drug resistance, EOC is the most common cause of mortality among gynecologic malignancies in China (2). EOC is mainly treated by surgery supplemented with chemotherapy, radiotherapy and biotherapy (3). However, the majority of patients are diagnosed at an advanced stage, easily exhibiting chemotherapy resistance. Consequently, chemotherapy effect is reduced, and the 5-year survival rate is low $(25-30 \%)(4,5)$. Multidrug resistance (MDR) is one of the major reasons for the failure of EOC chemotherapy during the advanced stage (6). This drug resistance is associated with the molecular activity and expression of drug pumps, abnormal $\mathrm{pH}$ of tumor cell, DNA damage repair ability, drug detoxification, apoptotic pathway and methylation of a number of genes, including BRAC1, BRAC2, MLH1 and FBX032 (7-10). MDR may be divided into primary drug resistance, that exists prior to chemotherapy treatment, and acquired drug resistance, which develops during chemotherapy (11). MDR can reduce the concentration of chemotherapeutic drugs in tumor cells and, therefore, the sensitivity of these tumor cells to drugs (12). In addition, the changes in methylation state of tumor cells can decrease the overall methylation state or increase the local methylation, therefore, causing tumor cells to resist chemotherapeutic drugs (13). The multidrug-resistance 1 (MDR1) gene product $\mathrm{P}$ glycoprotein is an efflux pump that actively transports substrates. In addition, lung resistance protein is a small subcellular structure located at cytoplasmic vaults that may be in charge of the subsequent exocytosis of agents from the cell. Furthermore, glutathione S-transferase-P1 is a 
phase II metabolic enzyme that protects cells from anticancer drug-induced injury. All aforementioned genes are involved in MDR (14). Therefore, the present study aims to investigate the expression and the role of the methylation state of MDR in different ovarian tissues of EOC, and to analyze the association between the methylation state of MDR and the clinicopathological features of EOC. In addition, the presents study aims to provide a theoretical basis for predicting individual responsiveness to chemotherapy and prognosis, and improving treatment.

\section{Materials and methods}

Patients and specimens. A total of fresh specimens (57 cases of PEOC, 34 cases of borderline adenoma and 21 cases of benign adenoma) were collected between March 2009 and July 2011 in Taihe Hospital (Shiyan, China). The average age of patients was between 35 and 71 years. Histologic cell types were as follows: 30 cases of serous adenocarcinoma, 20 cases of mucinous adenocarcinoma and 7 cases of endometrioid carcinoma in PEOC; 20 cases of serous adenocarcinoma, 10 cases of mucinous adenocarcinoma and 4 cases of endometrioid carcinoma in borderline adenoma; 13 cases of serous adenocarcinoma, 7 cases of mucinous adenocarcinoma and 1 cases of endometrioid carcinoma in benign adenoma. Clinical staging using the standards established by the International Federation of Obstetricians and Gynecologists (15) identified the following number of cases for each stage: Stage I, 25 cases; stage II, 19 cases; and stage III, 13 cases. Of these cases, 12 were well differentiated, 20 were moderately differentiated and 25 were poorly differentiated carcinomas. Histological diagnosis was based on the histological typing system of the World Health Organization (16) and the stage of disease was determined according to the International Federation of Gynecology and Obstetrics staging system (17). The diagnosis was confirmed by at least two experienced pathologists at the Department of Pathology of Taihe Hospital in a blinded manner. All patients had not received chemotherapy and radiation therapy prior to sample collection. Samples were stored in liquid nitrogen for future use. The integrity of clinical data was maintained, and the patients were followed up between 6 and 60 months. In accordance with the Declaration of Helsinki, the present study was approved by the Ethics Committee of Taihe Hospital (Shiyan, China), and written informed consent were obtained from all patients or their families.

Cell culture and zebularine treatment. Ovarian cancer cell line, A2780 and A2780/DDP (platinum-resistant), were provided by the Fourth Military Medical University (Xi'an, China) and cultivated at $37^{\circ} \mathrm{C}$ with $5 \% \mathrm{CO}_{2}$ in RPMI-1640 medium for $48 \mathrm{~h}$, containing $10 \%$ fetal bovine serum (Gibco; Thermo Fisher Scientific, Inc., Waltham, MA, USA), 1.5\% L-glutamine and $1 \%$ penicillin/streptomycin. Two to four generations of well-grown cells were obtained for testing, and the remaining cells were preserved in liquid nitrogen. A2780/DDP were treated with various doses $(0.0,0.2$ and $0.5 \mathrm{mM})$ of zebularine, a DNA Methyl Transferase inhibitor that acts similarly to 5-aza-dC, for $48 \mathrm{~h}$ at $37^{\circ} \mathrm{C}$ and were subsequently collected for cell apoptosis. A total of $1 \times 10^{6}$ cells were collected and washed with PBS three times. The collected cells were incubated with
$5 \mu 1$ propidium iodide (PI; Sigma-Aldrich; Merck KGaA, Darmstadt, Germany) and $5 \mu \mathrm{l}$ fluorescein isothiocyanate (FITC; Annexin V-FITC/PI kit; cat. no. E606336; Sangon Biotech Co., Ltd., Shanghai, China) for $1 \mathrm{~h}$ at $37^{\circ} \mathrm{C}$.

Cell apoptosis was detected using flow cytometry (Beckman Coulter, Inc., Brea, CA, USA) and cell Modifit software (version 3.1; Verity Software House, Inc., Topsham, ME, USA). All experiments were repeated six times.

Reverse transcription-quantitative polymerase chain reaction $(R T-q P C R)$. Total RNA were extracted from tissues and cells using TRIzol ${ }^{\circledR}$ Reagent (Thermo Fisher Scientific, Inc.), according to the manufacturer's protocols. The absorbance of RNA was determined at a wavelength of 260 and $280 \mathrm{~nm}$ with NanoDrop-2000 (Thermo Fisher Scientific, Inc.). cDNA was synthesized from RNA with Reverse Transcription system (Promega Corporation, Madison, WI, USA) and was used immediately or stored at $-80^{\circ} \mathrm{C}$ until use. The primers are presented in Table I. PCR amplification system (Sangon Biotech Co., Ltd.) included the following: $\mathrm{Mg}^{2+} 2.4 \mu \mathrm{l}, 5^{\prime}$ and 3' primer $2 \mu \mathrm{l}, 2 \mathrm{mmol} / \mathrm{l}$ dNTP $1.5 \mu \mathrm{l}$, 10X SYBR-Green I $1 \mu \mathrm{l}$, Taq $0.3 \mu \mathrm{l}, 10 \mathrm{x}$ Buffer $3 \mu \mathrm{l}$, cDNA5 $\mu \mathrm{l}$, with sterile water total volume filled $30 \mu \mathrm{l}$. The thermocycling conditions were as follows: $95^{\circ} \mathrm{C}$ denaturation for $5 \mathrm{~min}, 94^{\circ} \mathrm{C}$ for $30 \mathrm{sec}, 60^{\circ} \mathrm{C}$ for $30 \mathrm{sec}, 72^{\circ} \mathrm{C}$ for $1 \mathrm{~min}$ with 35 cycles. Dissociation curve analysis was performed at the end point of the PCR cycles. GSTP1, LRP and MDR1 expression levels were normalized to GAPDH in each sample, and were determined using the $2^{-\Delta \Delta C q}$ method (18).

Western blot analysis. Total protein of cells and tissues was extracted using the Total Protein Extraction kit (Sangon Biotech Co., Ltd.) and concentrations were determined with NanoDrop-2000 (NanoDrop; Thermo Fisher Scientific, Inc., Wilmington, DE, USA). A total $10 \mu \mathrm{g}$ protein was loaded onto $10 \%$ SDS-PAGE for electrophoresis and transferred to polyvinylidene difluoride membranes. Following transfer, protein blots were blocked with 5\% non-fat dry milk-TBS- $0.1 \%$ Tween-20 for $2 \mathrm{~h}$ at room temperature and subsequently washed three times with TBS- $0.1 \%$ Tween-20 for $10 \mathrm{~min}$, and incubated overnight at $4{ }^{\circ} \mathrm{C}$ with primary polyclonal antibodies against P-GP (1:1,000 dilution; cat. no. MAB-0237; Maxim-Bio Ltd., Fuzhou, China), LRP (1:1,000 dilution; cat. no. MAB-0319; Maxim-Bio Ltd.) and GSTP1 (1:1,000 dilution; cat. no. MAB-0583; Maxim-Bio Ltd.), according to the manufacturer's protocols. Signals were detected following incubation for $2 \mathrm{~h}$ at room temperature in horseradish peroxidase-conjugated secondary antibody (1:1,000 dilution; cat. no. KIT-C10; Maxim-Bio Ltd.). Protein bands were detected using an enhanced chemiluminescence kit (GE Healthcare, Chicago, IL, USA). The optical density of the bands was determined using ImageJ $2 \mathrm{x}$ software (version 2.1.4.7; National Institutes of Health, Bethesda, MD, USA). GAPDH (1:1,000 dilution; cat. no. MAB-97166; Cell Signaling Technology, Inc., Danvers, MA, USA) acted as the reference protein for the loading control.

DNA isolation and bisulfite conversion of target DNA. Tissue DNA was extracted through proteinase $\mathrm{K}$ treatment, phenol/chloroform/isoamylalcohol extraction and ethanol 
Table I. Primers sequences of gene expression and methylation.

\begin{tabular}{lllr}
\hline Gene & \multicolumn{1}{c}{ Forward (5'-3') } & \multicolumn{1}{c}{ Reverse (5'-3') } & Product (bp) \\
\hline MDR1 & CCCATCATTGCAATAGCAGG & TGTTCAAACTTCTGCTCCTGA & 158 \\
LRP & GTCTTCGGGCCTGAGCTGGTGTCG & CTTGGCCGTCTCTTGGGGGTCCTT & 240 \\
GSTP1 & CCAGAACCAGGGAGGCAAGA & GAGGCGCCCCACATATGCT & 325 \\
RASSF1A & GGCGTCGTGCGCAAAGGCC & GGG TGGCTTCTTGCTGGAGGG & 330 \\
GAPDH & GAAGGTGAAGGTCGGAGTC & GAAGATGGTGATGGGATTTC & 226 \\
Methylation & GTGTTAACGCGTTGCGTATC & AACCCCGCGAACTAAAAACGA & 93 \\
Un-methylation & TTTGGTTGGAGTGTGTTAATGTG & CAAACCCCACAAACTAAAAACAA & 105 \\
\hline
\end{tabular}

MDR1, multidrug resistance 1; LRP, lung resistance protein; GSTP1, placental glutathione S-transferase-P1; RASSF1A, Ras association domain family member.

precipitation in sequence. Bisulfite conversion was carried out with modified Herman's method (19). The conversion was based on the principle that DNA, treated with bisulfite, would result in the conversion of unmethylated cytosine residues into uracil. Methylated cytosine residues, on the other hand, would remain unchanged. Therefore, the DNA sequences of methylated and unmethylated genomic regions following bisulfite conversion would differ and would be distinguished by sequence-specific PCR primers. The bisulfite conversion of target DNA was stored at $-20^{\circ} \mathrm{C}$ prior to methylation-specific PCR (MSP) for 2 months.

MSP. The primers that were used for MSP of the Ras association domain family member 1 (RASSF1A) gene are presented in Table I. PCR amplification system included: $\mathrm{Mg}^{2+} 2.4 \mu \mathrm{l}$, $0.8 \mu 1$ each of the $5^{\prime}$ and $3^{\prime}$ primer, Taq $0.3 \mu 1$, dNTP $1.6 \mu 1$, $10 \mathrm{X}$ buffer $2 \mu \mathrm{l}$, bisulfite conversion of target DNA $0.5 \mu \mathrm{l}$, total volume filled to $20 \mu \mathrm{l}$ with sterile water. The thermocycling conditions were as follows: $94^{\circ} \mathrm{C}$ denaturation for $5 \mathrm{~min}, 94^{\circ} \mathrm{C}$ for $30 \mathrm{sec}, 60^{\circ} \mathrm{C}$ for $45 \mathrm{sec}$ and $72^{\circ} \mathrm{C}$ for 1 min with 35 cycles. Additionally, a final extension for $5 \mathrm{~min}$ at $70^{\circ} \mathrm{C}$ was performed. The reaction products were separated electrophoretically on a $2 \%$ agarose gel and stained with ethidium bromide for further confirmation of the PCR products.

Statistical analysis. Statistical calculations were performed using SPSS software 16.0 (SPSS, Inc., Chicago, IL, USA), and $\mathrm{P}<0.05$ was considered to indicate a statistically significant difference. The measured data were expressed as the mean \pm standard deviation. One-way analysis of variance followed by Dunnett's T3 post hoc test, two-tailed $\chi^{2}$ test and multivariate logistic regression analysis were used to compare difference among groups. Kaplan-Meier analysis was used to plot survival curves and the survival curves were compared using the two-sided data log-rank method.

\section{Results}

$m R N A / p r o t e i n$ expression of MDRl (P-gp), LRP, GSTP1, RASSF1A and methylation frequency of RASSF1A in all samples. The mRNA expression of MDR1, LRP and GSTP1 was detected in 57 cases of PEOC, 34 cases of borderline adenoma and 21 cases of benign adenoma by RT-qPCR. The resistance genes/proteins MDR1 (P-gp), LRP and GSTP1 were highly expressed in PEOC compared with in borderline adenoma, and the resistance gene positive expression rates were $56.1,78.9$ and $57.9 \%$, while the protein positive expression rates were $52.6,70.2$ and $56.1 \%$, respectively. In borderline adenoma, their positive expression rates were $26.5,35.3$ and $26.5 \%$, while the protein positive expression rates were 23.5, 29.4 and $23.5 \%$, respectively (data not shown). However, in benign adenoma, the resistance genes/proteins were either poorly expressed or not expressed at all (Fig. 1A-C). The expression levels of the resistance genes/proteins were significantly higher in PEOC tissues/borderline adenoma tissues compared with benign adenoma tissues $(\mathrm{P}<0.001)$.

The methylation status of RASSF1A was analyzed using MSP assay in all samples. Methylation products were indicated with 33/57 (57.9\%), 13/34 (38.2\%) and 3/21 (14.3\%) in PEOC, borderline adenoma and benign adenoma, respectively. Hypermethylation and low expression of RASSF1A gene was detected in all cancer tissues (Fig. 1D).

mRNA expression, gene methylation and survival time in different clinicopathological data of PEOC. The expression of resistance genes was significantly higher in well and moderately differentiated carcinoma compared with poorly differentiated carcinomas $(\mathrm{P}<0.05$; Table II). In addition, the difference in other clinicopathological factors, including age, pathological type, and clinical stage was not statistically significant. The survival time was higher in well and moderately differentiated carcinoma compared with poorly differentiated carcinomas, however not statistically significant. The association between the expression levels of the resistance genes/gene methylation and the clinicopathological features are presented in Table II.

mRNA/protein expression of MDR1 (P-gp), LRP and GSTP1 in $A 2780$ and $A 2780 / D D P$. To study the role of methylation in the acquired drug-resistance of ovarian cancer, the changes of drug-resistance gene/protein expression in A2780 and A2780/DDP cells was examined. It was indicated that the resistance genes/protein were either poorly expressed or not expressed in A2780 cell lines, however highly expressed in A2780/DDP. The difference indicated to be statistically significant (Fig. 2). In addition, following further treatment of A2780/DDP with different concentrations of de-methylation reagents, including zebularine, the expression levels of drug 


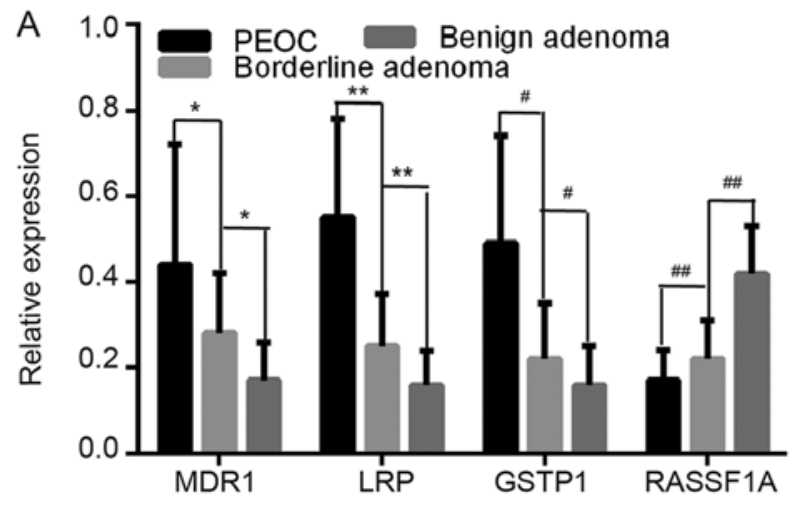

C

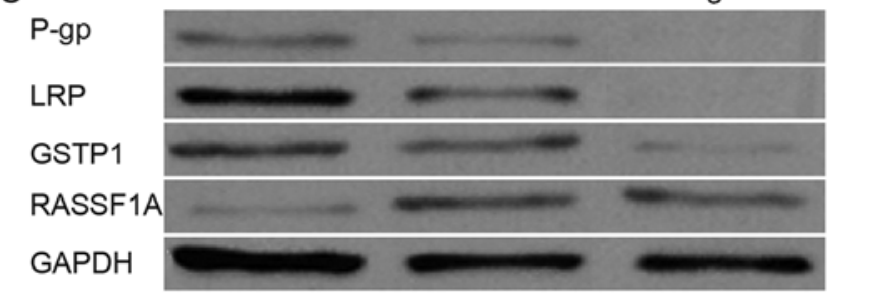

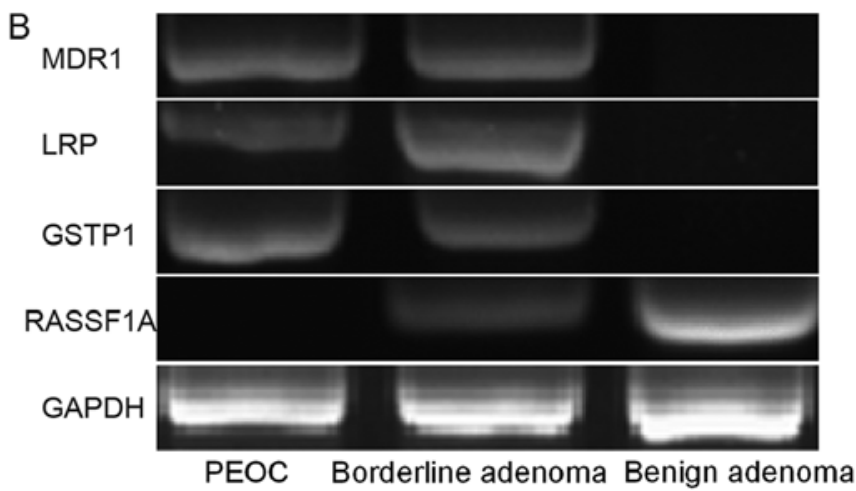

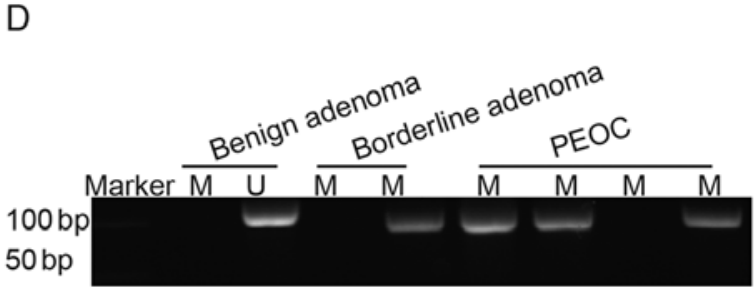

Figure 1. The mRNA/protein expression of MDR1 (P-gp), LRP, GSTP1, RASSF1A and methylation frequency of RASSF1A in all samples. (A) mRNA relative expression levels of resistance genes in PEOC, benign adenoma and borderline adenoma. (B) Different gene expressions in PEOC, borderline adenoma and benign adenoma. (C) Different protein expressions in PEOC, borderline adenoma and benign adenoma. (D) Representation of methylated and unmethylated products of RASSF1A in all sample. ${ }^{*} \mathrm{P}<0.01,{ }^{* *} \mathrm{P}<0.01,{ }^{\#} \mathrm{P}<0.01,{ }^{\# \#} \mathrm{P}<0.01$. M, methylated; U, un-methylated; MDR1, multidrug resistance 1 ; LRP, lung resistance protein; GSTP1, placental glutathione S-transferase-P1; RASSF1A, Ras association domain family member; P-gp, product P glycoprotein; PEOC, primary epithelial ovarian cancer.

resistance genes/proteins were decreased and apoptotic rate was increased (Figs. 3 and 4). RASSF1A gene methylation was weakened and unmethylation was increased. Furthermore, the expression level of RASSF1A gene/protein expression gradually increased (Fig. 5).

Clinicopathology, gene expression level, gene methylation and survival rate of patients with PEOC. Risk modeling and multivariate logistic analysis indicated that the prognostic factors of EOC were associated with high expression levels of LRP and GSTP1 (Table III), however not with age, stage, degree of differentiation, RASSF1A methylation and MDR1 expression (data not shown). The cases were categorized into positive and negative groups, according to the expression levels of LRP and GSTP1. The survival curve of the negative group, non-expression of LRP and GSTP1, was significantly higher compared with the positive group $(\mathrm{P}<0.05$; Fig. 6$)$.

\section{Discussion}

Tumor cells may develop MDR to various chemotherapy regimens, such as paclitaxel and carboplatin or docetaxel and carboplatin (9). MDR resistance reduces the sensitivity of tumor cells to chemotherapy drugs, leading to the failure of ovarian cancer treatment and disease progression. MDR was identified as an important cause leading to failure of cancer treatment (9).

The MDR1 gene encodes the glycoprotein drug transporter $\mathrm{P}$-gp. Elevated MDR1 genes or P-gp protein have been reported to be associated with drug resistance (20). MDR1/P-gp expression is mainly mediated by alkylating agents (21). LRP serves an important role in various tumors, including gastric cancer and non-small cell lung cancer, with drug resistance $(22,23)$. Its increased expression can mainly make tumor cells resistant to cisplatin (24). The aberrant methylation of RASSF1A gene serves an important role in the occurrence and development of various tumors, including bladder cancer and thyroid cancer $(25,26)$, and is associated with drug resistance and tumor prognosis $(27,28)$. The purpose of the present study was to detect the expression of drug resistance genes and aberrant methylation of RASSF1A in different types of ovarian tissues and to investigate their role in the primary resistance of ovarian cancer.

This study indicated that the expression levels of resistance genes MDR1, LRP and GSTP1 in epithelial ovarian cancer were significantly higher compared with those in borderline adenoma and benign adenoma. Furthermore, all patients had not received any prior chemotherapy and radiation therapy. This phenomenon suggested that primary drug resistance was associated with PEOC. Co-expression of three genes/proteins in cancer tissues, suggesting the expression of drug resistance genes, is indicated to be regulated by certain factors, such as DNA methylation, commonly causing ovarian cancer MDR (9).

The expression level of the drug resistance genes was higher in well and moderately differentiated carcinomas compared with poorly differentiated tissues. This finding suggested that high degree of cancer differentiation indicates strong resistance to chemotherapeutic drugs. In addition, an association was indicated to exist between RASSF1A methylation state and PEOC differentiation degree. Choi et al (29) reported that the abnormal methylation of RASSF1A gene indicated a gradual increasing trend from benign tumor to cancer. This result 
Table II. Association between expression of gene, methylation, survival time and clinicopathological parameters in primary epithelial ovarian cancer.

\begin{tabular}{|c|c|c|c|c|c|c|}
\hline Study groups & $\mathrm{n}$ & $\begin{array}{l}\text { Multi-drug } \\
\text { resistance gene }\end{array}$ & $\begin{array}{l}\text { Lung resistance } \\
\text { protein }\end{array}$ & $\begin{array}{l}\text { Placental glutathione } \\
\text { S-transferase-P1 }\end{array}$ & $\begin{array}{c}\text { Methylation } \\
\text { Positive \% }\end{array}$ & Survival time \\
\hline \multicolumn{7}{|l|}{ Age (years) } \\
\hline$<50$ & 19 & $0.45 \pm 0.31$ & $0.61 \pm 0.25$ & $0.50 \pm 0.24$ & $47.4(9 / 19)$ & $41.0 \pm 19.1$ \\
\hline$\geq 50$ & 38 & $0.44 \pm 0.27$ & $0.52 \pm 0.22$ & $0.43 \pm 0.26$ & $63.2(24 / 38)$ & $39.2 \pm 16.5$ \\
\hline \multicolumn{7}{|l|}{ Histologic types } \\
\hline Serous adenocarcinoma & 30 & $0.50 \pm 0.27$ & $0.61 \pm 0.26$ & $0.54 \pm 0.21$ & $53.3(16 / 30)$ & $41.3 \pm 18.3$ \\
\hline Mucinous + Endometrioid & 27 & $0.37 \pm 0.28$ & $0.50 \pm 0.19$ & $0.43 \pm 0.28$ & $63.0(17 / 27)$ & $38.2 \pm 16.3$ \\
\hline \multicolumn{7}{|l|}{ Stage } \\
\hline $\mathrm{I}+\mathrm{II}$ & 25 & $0.49 \pm 0.29$ & $0.62 \pm 0.24$ & $0.54 \pm 0.23$ & $40.0(10 / 25)^{\mathrm{b}}$ & $40.2 \pm 18.4$ \\
\hline $\mathrm{III}+\mathrm{IV}$ & 32 & $0.40 \pm 0.26$ & $0.51 \pm 0.22$ & $0.45 \pm 0.27$ & $71.9(23 / 32)$ & $39.5 \pm 16.6$ \\
\hline \multicolumn{7}{|l|}{ Differentiation } \\
\hline Well+Moderately & 32 & $0.51 \pm 0.26^{\mathrm{a}}$ & $0.61 \pm 0.25^{\mathrm{a}}$ & $0.56 \pm 0.23^{\mathrm{a}}$ & $43.8(14 / 32)^{\mathrm{c}}$ & $41.6 \pm 18.1$ \\
\hline Poorly & 25 & $0.35 \pm 0.28$ & $0.48 \pm 0.18$ & $0.41 \pm 0.27$ & $72.0(18 / 25)$ & $37.5 \pm 16.3$ \\
\hline
\end{tabular}

${ }^{\mathrm{a}} \mathrm{P}=0.03$ vs. poorly, ${ }^{\mathrm{b}} \mathrm{P}=0.016$ vs. III $+\mathrm{IV},{ }^{\mathrm{c}} \mathrm{P}=0.033$ vs. poorly. Gene expression and survival time data were expressed as the mean \pm standard deviation.
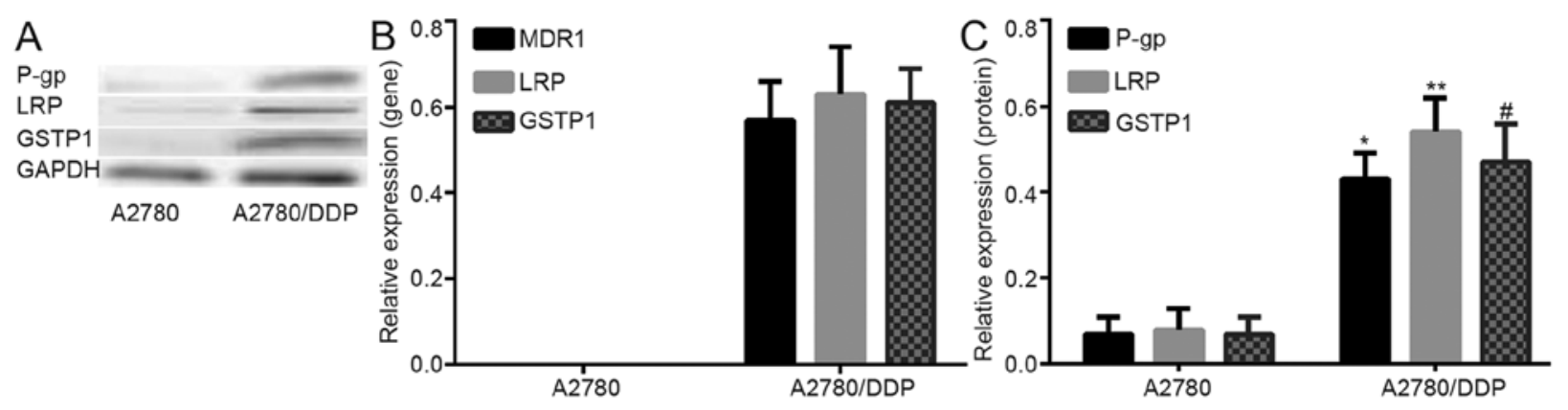

Figure 2. The expression levels of resistance genes/protein in A2780 and A2780/DDP cells. (A) Different protein expressions in LRP, GSTP1 and P-gp protein in A2780 and A2780/DDP cells. (B) mRNA relative expression of in MDR1, GSTP1 and P-gp gene in A2780 and A2780/DDP cells. (C) Relative expression of LRP, GSTP1 and P-gp protein in A2780 and A2780/DDP cells. ${ }^{*} \mathrm{P}<0.001$ vs. A2780; ${ }^{* *} \mathrm{P}<0.001$ vs. A2780; ${ }^{*} \mathrm{P}<0.001$ vs. A2780. MDR1, multidrug resistance 1; LRP, lung resistance protein; GSTP1, placental glutathione S-transferase-P1; P-gp, product P glycoprotein.
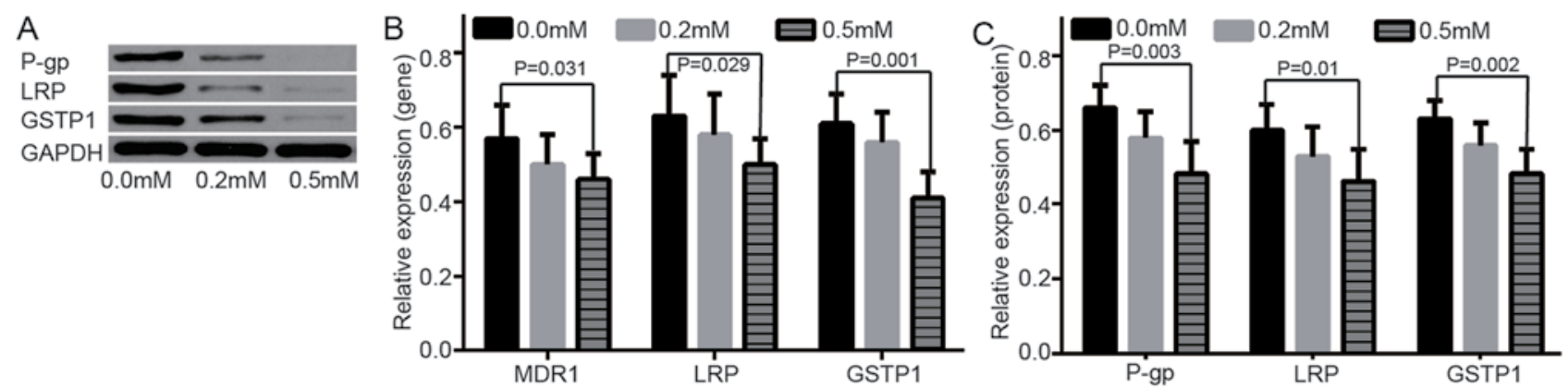

Figure 3. Evaluation of expression of resistance genes/proteins at $0.0 \mathrm{mM}, 0.2 \mathrm{mM}, 0.5 \mathrm{mM}$ of zebularine. (A) Different protein expressions in LRP, GSTP1 and P-gp at different concentrations of zebularine. (B) mRNA relative expressions of MDR1, GSTP1 and P-gp gene at $0.0 \mathrm{mM}, 0.2 \mathrm{mM}, 0.5 \mathrm{~m}$ zebularine. (C) Relative expressions of LRP, GSTP1 and P-gp protein at different concentrations of zebularine. MDR1, multidrug resistance 1; LRP, lung resistance protein; GSTP1, placental glutathione S-transferase-P1; P-gp, product P glycoprotein.

indicated that abnormal methylation can gradually accumulate and finally result in PEOC occurrence. In addition, methylation changes commonly occur prior to solid tumors. This change also participates in the occurrence and development of malignant epithelial ovarian tumor (9). In addition, RASSF1A gene can assist the paclitaxel chemotherapeutic drugs in interfering 

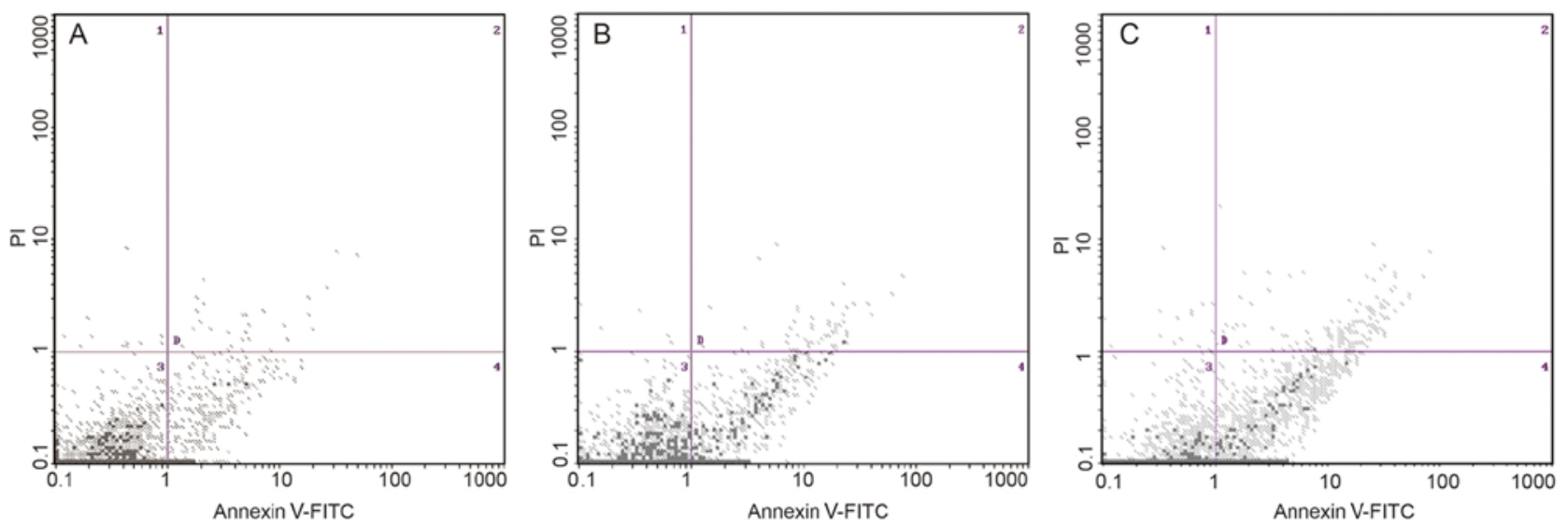

Figure 4. Apoptotic cells (A2780/DDP) were measured by Annexin V/PI stain using flow cytometry analysis. Apoptotic rate was measured at different zebularine concentrations, including (A) $0.0 \mathrm{mM}$, (B) $0.2 \mathrm{mM}$ and (C) $0.5 \mathrm{mM}$. PI, propidium iodide; FITC, Fluorescein isothiocyanate.
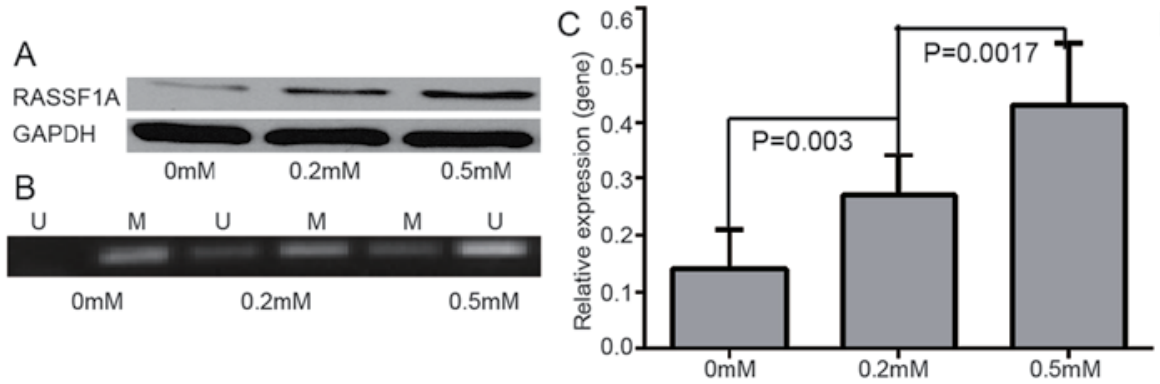

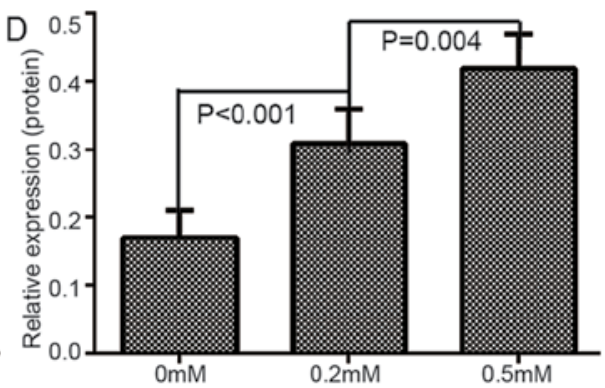

Figure 5. Changes in gene expression and methylation levels following treatment with different zebularine concentrations. (A) RASSF1A protein expression at different zebularine concentrations. (B) Representation of methylated and unmethylated products of RASSF1A. (C) Relative mRNA expression levels of RASSF1A gene. (D) Relative protein expression levels of RASSF1A. M, methylated; U, un-methylated; RASSF1A, Ras association domain family member.

with the spindle polymerization in normal cases (28). The loss of RASSF1A protein expression can cause the drug resistance to paclitaxel in PEOC cell, however, the activation of RASSF1A expression through demethylation can recover the paclitaxel sensitivity (29). This result suggests that RASSF1A methylation may be associated with PEOC drug resistance (30). In the present study, RASSF1A methylation was not a prognostic risk factor, suggesting that MDR is a complex process of multigene, multistep, and the cross action of multifactor.

Zebularine is a DNA methyl transferase inhibitor, acting similarly to 5-aza-dC, however is more specific and therefore, less toxic compared with 5-AzaC (31). In the present study, zebularine treatment induced cell apoptosis at doses of $0.5 \mathrm{mM}$ in A2780/DDP, implying that zebularine-induced A2780/DDP cell growth inhibition was due to cell apoptosis. However, with the increase of zebularine concentration, the genes/protein expression decreased. This result implied that zebularine is an important antiproliferative agent against A2780/DDP. With increasing concentration of zebularine, the level of methylation decreased and the level of un-methylation increased. This finding indicated that zebularine could reverse the methylation state of the RASSF1A gene in A2780/DDP. RT-qPCR and western blot analysis also confirmed that zebularine may increase the expression of RASSF1A gene at mRNA and protein expression levels. Low expression caused by hypermethylation of RASSF1A gene may serve an important role in cancer-acquired resistance in PEOC.
High expression of resistance genes is the main cause of tumor cell resistance to chemotherapy. Hou et al (32) reported that the drug resistance of P-gp was proportionate to its high expression in PEOC drug-resistant strain. Curcumin can reduce $\mathrm{P}-\mathrm{gp}$ biosynthesis and inhibit P-gp biological activity to enhance the cytotoxicity of drugs to tumor cell and reduce the drug resistance of tumor cells. Furthermore, Cao et al (33) demonstrated that LRP expression was reduced subsequent to curcumin acting on the drug-resistant hepatoma cells. Chemotherapy drugs significantly increased the intracellular concentration and toxicity, therefore, reversing drug resistance (33). Wang et al (34) indicated that the TGFBI methylation level of the cell line is higher compared with that of sensitive cells. Following 5-aza-dc treatment, the TGFBI mRNA and protein expression levels in drug resistant cell line increased significantly. This result implied that the re-expression of TGFBI can reverse paclitaxel drug resistance (34). Therefore, reduced expression of drug-resistant genes is likely to reverse the drug resistance. Further studies on reversing solid tumor drug resistance are required to provide an experimental basis.

Yang et al (11) reported that the MDR1 expression in patients with cervical cancer of the negative-group survival curves was higher compared with that of the positive group. In the present study, high LRP and GSTP1 mRNA expression were associated with the survival rates of patients with PEOC. The expression of LRP and GSTP1 in the patients of the negative-group survival curves was higher compared 
Table III. Multivariate logistics analysis on influencing factors for primary epithelial ovarian cancer prognosis.

\begin{tabular}{|c|c|c|c|c|c|c|}
\hline \multirow[b]{2}{*}{ Characteristics } & \multicolumn{3}{|c|}{ Univariate analysis } & \multicolumn{3}{|c|}{ Multivariate analysis } \\
\hline & B & $\operatorname{Exp}(\mathrm{B})$ & P-value & B & $\operatorname{Exp}(\mathrm{B})$ & P-value \\
\hline $\begin{array}{l}\text { Lung resistance protein } \\
\text { positive vs. negative }\end{array}$ & 2.72 & 0.065 & 0.003 & & & \\
\hline $\begin{array}{l}\text { Placental glutathione S-transferase-P1 } \\
\text { positive vs. negative }\end{array}$ & 3.06 & 0.047 & $<0.001$ & 1.58 & 4.84 & 0.001 \\
\hline
\end{tabular}

B, regression coefficient; $\operatorname{Exp}(\mathrm{B})$, odds ratio.
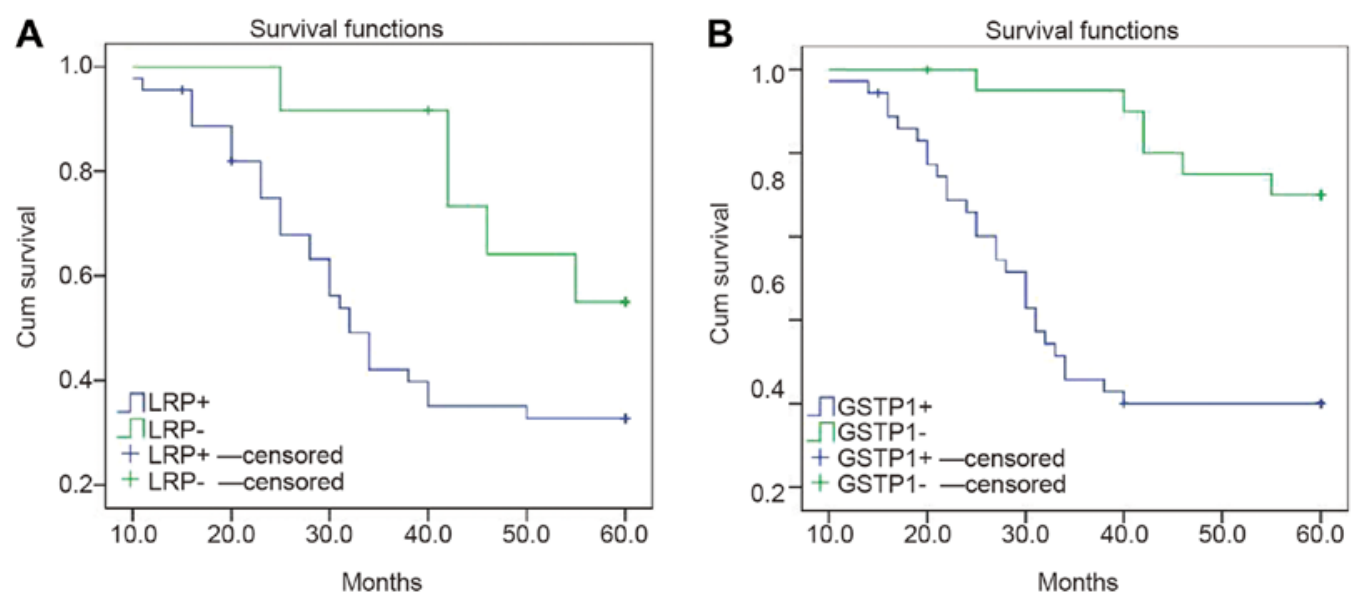

Figure 6. Survival curves of patients with LRP, GSTP1 mRNA-positive and negative expression levels. Survival curve of patients with (A) LRP positive and negative expression. (B) Survival curve of patients with GSTP1 positive and negative expression. Censored represents the number of cases eliminated for various reasons. LRP, lung resistance protein; GSTP1, placental glutathione S-transferase-P1.

with the patients in the positive group. This result suggested that the expression of LRP and GSTP1 in patients with PEOC is a high-risk prognostic factor. In addition, Chiang et al (35) reported that patients with zinc finger MYND-type containing 10 (BLU) methylation exhibited short progression free survival (PFS) and overall survival time. BLU can also enhance paclitaxel to induce the apoptosis of EOC cells subsequent to recovering its expression (35). BLU methylation may be an indicator in the evaluation of EOC prognosis. This result reveals that the change in methylation state of drug-resistant genes is also likely to reverse the drug resistance (35).

In conclusion, high expression of resistance genes and methylation of RASSF1A gene may be one of the important mechanisms of primary ovarian cancer MDR. The expression and methylation detection of resistance genes may provide novel guidance to predict the effect of ovarian cancer chemotherapy and to assist the chemotherapy regimen. However, due to cost, a number of experiments were not carried out, including cell transfection and experiments on animals. In subsequent experiments, the aim is to provide further studies on the mechanism of drug resistance.

\section{Acknowledgements}

Not applicable.

\section{Funding}

The present study was funded by Taihe Hospital Projects (grant nos. 2016JZ26, 2017JJXM044 and 2014JJXM019).

\section{Availability of data and materials}

The datasets used and/or analyzed during the current study are available from the corresponding author on reasonable request.

\section{Authors' contributions}

BG and DL conceived and designed the study. FY, WC and YL performed the experiments. RL and XH analyzed the data. BG wrote the manuscript.

\section{Ethics approval and consent to participate}

In accordance with the Declaration of Helsinki, the present study was approved by the Ethics Committee of Taihe Hospital (Shiyan, China), and written informed consent was obtained from all patients or their families.

\section{Patient consent for publication}

Not applicable. 


\section{Competing interests}

The authors declare that they have no competing interests.

\section{References}

1. Lheureux S, Gourley C, Vergote I and Oza AM: Epithelial ovarian cancer. Lancet 393: 1240-1253, 2019.

2. Chen W, Zheng R, Baade PD, Zhang S, Zeng H, Bray F, Jemal A, Yu XQ and He J: Cancer statistics in China, 2015. CA Cancer J Clin 66: 115-132, 2016

3. Marcus CS, Maxwell GL, Darcy KM, Hamilton CA and McGuire WP: Current approaches and challenges in managing and monitoring treatment response in ovarian cancer. J Cancer 5: 25-30, 2014.

4. Ledermann JA, Raja FA, Fotopoulou C, Gonzalez-Martin A, Colombo N and Sessa C; ESMO Guidelines Working Group: Newly diagnosed and relapsed epithelial ovarian carcinoma: ESMO Clinical Practice Guidelines for diagnosis, treatment and follow-up. Ann Oncol 24: vi24-vi32, 2013.

5. Asgari Z, Rouholamin S, Hosseini R, Sepidarkish M, Hafizi L and Javaheri A: Comparing ovarian reserve after laparoscopic excision of endometriotic cysts and hemostasis achieved either by bipolar coagulation or suturing: A randomized clinical trial. Arch Gynecol Obstet 293: 1015-1022, 2016.

6. Qin L, Qiu H, Zhang M, Zhang F, Yang H, Yang L, Jia L, Qin K, Jia L, Dou X, et al: Soluble CD40 ligands sensitize the epithelial ovarian cancer cells to cisplatin treatment. Biomed Pharmacother 79: 166-175, 2016.

7. Yang F, Gao B, Chen W, Du E, Liang Y, Hu X and Yang X: Expression of resistance gene and prognosis of chemotherapy in primary epithelial ovarian cancer. Medicine (Baltimore) 97: e12364, 2018

8. Matei D, Fang F, Shen C, Schilder J, Arnold A, Zeng Y, Berry WA, Huang $T$ and Nephew KP: Epigenetic resensitization to platinum in ovarian cancer. Cancer Res 72: 2197-2205, 2012.

9. Yin F, Liu X, Li D, Wang Q, Zhang W and Li L: Tumor suppressor genes associated with drug resistance in ovarian cancer (review). Oncol Rep 30: 3-10, 2013

10. Chaudhry P, Srinivasan R and Patel FD: Utility of gene promoter methylation in prediction of response to platinum-based chemotherapy in epithelial ovarian cancer (EOC). Cancer Invest 27: 877-884, 2009.

11. Yang F, Gao B, Li R, Li W, Chen W, Yu Z and Zhang J: Expression levels of resistant genes affect cervical cancer prognosis. Mol Med Rep 15: 2802-2806, 2017.

12. Koh I, Hinoi T, Sentani K, Hirata E, Nosaka S, Niitsu H, Miguchi M, Adachi T, Yasui W, Ohdan H and Kudo Y: Regulation of multidrug resistance 1 expression by CDX2 in ovarian mucinous adenocarcinoma. Cancer Med 5: 1546-1555, 2016.

13. Balch C, Huang TH, Brown R and Nephew KP: The epigenetics of ovarian cancer drug resistance and resensitization. Am J Obstet Gynecol 191: 1552-1572, 2004

14. Lu C, Shan Z, Li C and Yang L: MiR-129 regulates cisplatin-resistance in human gastric cancer cells by targeting P-gp. Biomed Pharmacother 86: 450-456, 2017.

15. Javadi S, Ganeshan DM, Qayyum A, Iyer RB and Bhosale P. Ovarian cancer, the revised FIGO staging system and the role of imaging. AJR Am J Roentgenol 206: 1351-1360, 2016.

16. Kurman RJ, Carcangiu ML, Herrington CS and Young RH WHO Classification of Tumours of Female Reproductive Organs. 4th edition. International Agency for Research on Cancer, p307, 2014.

17. Prat J; FIGO Committee on Gynecologic Oncology: Staging classification for cancer of the ovary, fallopian tube, and peritoneum. Int J Gynaecol Obstet 124: 1-5, 2014.

18. Livak KJ and Schmittgen TD: Analysis of relative gene expression data using real-time quantitative PCR and the 2(-Delta Delta C(T)) method. Methods 25: 402-408, 2001.
19. Herman JG, Graff JR, Myöhänen S, Nelkin BD and Baylin SB Methylation-specific PCR: A novel PCR assay for methylation status of $\mathrm{CpG}$ islands. Proc Natl Acad Sci USA 93: 9821-9826, 1996.

20. Yuan Z, Shi X, Qiu Y, Jia T, Yuan X, Zou Y, Liu C, Yu H, Yuan Y, He X, et al: Reversal of P-gp-mediated multidrug resistance in colon cancer by cinobufagin. Oncol Rep 37: 1815-1825, 2017.

21. Stewart DJ: Tumor and host factors that may limit efficacy of chemotherapy in non-small cell and small cell lung cancer. Crit Rev Oncol Hematol 75: 173-264, 2010.

22. Zhang KG, Qin CY, Wang HQ, Wang JX and Wang QM: The effect of TRAIL on the expression of multidrug resistant genes MDR1, LRP and GST- $\pi$ in drug-resistant gastric cancer cell SGC7901/VCR. Hepatogastroenterology 59: 2672-2676, 2012.

23. Wei H, Lu W, Li M, Zhang Q and Lu S: Concomitance of P-gp/LRP expression with EGFR mutations in exons 19 and 21 in non-small cell lung cancers. Yonsei Med J 57: 50-57, 2016.

24. Jiao JW and Wen F: Tanshinone IIA acts via p38 MAPK to induce apoptosis and the down-regulation of ERCC1 and lung-resistance protein in cisplatin-resistant ovarian cancer cells. Oncol Rep 25 781-788, 2011.

25. Zhan L, Zhang B, Tan Y, Yang C, Huang C, Wu Q, Zhang Y, Chen X, Zhou M and Shu A: Quantitative assessment of the relationship between RASSF1A gene promoter methylation and bladder cancer (PRISMA). Medicine (Baltimore) 96: e6097, 2017.

26. Shou F, Xu F, Li G, Zhao Z, Mao Y, Yang F, Wang H and Guo H: RASSF1A promoter methylation is associated with increased risk of thyroid cancer: A meta-analysis. Onco Targets Ther 10: 247-257, 2017.

27. Vos MD, Martinez A, Elam C, Dallol A, Taylor BJ, Latif F and Clark GJ: A role for the RASSF1A tumor suppressor in the regulation of tubulin polymerization and genomic stability. Cancer Res 64: 4244-4250, 2004

28. Kassler S, Donninger H, Birrer MJ and Clark GJ: RASSF1A and the taxol response in ovarian cancer. Mol Biol Int 2012: 263267, 2012.

29. Choi YL, Kang SY, Shin YK, Choi JS, Kim SH, Lee SJ, Bae DS and Ahn G: Aberrant hypermethylation of RASSF1A promoter in ovarian borderline tumors and carcinomas. Virchows Arch 448: 331-336, 2006.

30. Pronina IV, Loginov VI, Kholdyrev DS, Kazubskaia TP and Braga ÉA: Alterations of expression level of RASSFIA gene in primary epithelial tumors of various locations. Mol Biol (Mosk) 46: 260-268, 2012 (In Russian).

31. Balch C, Yan P, Craft T, Young S, Skalnik DG, Huang TH and Nephew KP: Antimitogenic and chemosensitizing effects of the methylation inhibitor zebularine in ovarian cancer. Mol Cancer Ther 4: 1505-1514, 2005.

32. Hou XL, Takahashi K, Tanaka K, Tougou K, Qiu F, Komatsu K, Takahashi $\mathrm{K}$ and Azuma J: Curcuma drugs and curcumin regulate the expression and function of P-gp in Caco-2 cells in completely opposite ways. Int J Pharm 358: 224-229, 2008.

33. Cao SQ, Li P, Yin TY and Yang SL: Curcumin reverses multi-drugresistance of human hepatocellular carcinoma bel7402/5-FU cells. World Chin J Digestol 20: 135-139, 2012

34. Wang N, Zhang H, Yao Q, Wang Y, Dai S and Yang X: TGFBI promoter hypermethylation correlating with paclitaxel chemoresistance in ovarian cancer. J Exp Clin Cancer Res 31: 6, 2012.

35. Chiang YC, Chang MC, Chen PJ, Wu MM, Hsieh CY, Cheng WF and Chen CA: Epigenetic silencing of BLU through interfering apoptosis results in chemoresistance and poor prognosis of ovarian serous carcinoma patients. Endocr Relat Cancer 20: 213-227, 2013. 